example comparing infusional 5FU/FA+oxaliplatin with bolus 5FU/FA+irinotecan.

As NICE has now approved irinotecan as second-line therapy, there is a concern that in FOCUS the crossover for patients will be asymmetric. Patients initially having oxaliplatin could expect to crossover (i.e. receive irinotecan as salvage therapy), whereas those initially on irinotecan would not be able to crossover to oxaliplatin, as it is not licensed or approved in this indication. To address this situation the Trial Management Group (TMG) has suggested that, in those patients fit enough to receive it, a planned crossover treatment be designed. The TSC approved this request at their meeting on 19th June, and this will be implemented as soon as possible. This will ensure that every patient entering FOCUS will potentially have access to irinotecan and oxaliplatin at some point.

The TSC, DMEC and TMG believe that FOCUS remains a key trial despite the studies quoted in your editorial. We support its continued accrual, and encourage existing participants and new centres to enter patients. Only in this way can we clarify the use and sequencing of combination chemotherapy as quickly as possible.

\title{
REFERENCES
}

Cunningham D, Begent R, Bessell E, Bridgewater J, Carmichael J, Cassidy J, Coxon F, Daniel F, Falk S, Gildersleve J, Glynne-Jones R, Hawkins R, Hickish T, Hill $M$, Hochauser D, Iveson T, James R, Levine $\mathrm{E}$, Mainwaring P, Maraveyas A, O'Byrne K, Radstone D, Saunders M, Smith D, Steward W, Twelves C, Valle J, Wasan H (2002) Cancer patients' treatment limited. The Daily Telegraph. London.

de Gramont A, Bosset JF, Milan C, Rougier P, Bouche O, Etienne PL, Morvan F, Louvet C, Guillot T, Francois E, Bedenne L (1997) Randomized trial comparing monthly low-dose leucovorin and fluorouracil bolus with bimonthly high-dose leucovorin and fluorouracil bolus plus continuous infusion for advanced colorectal cancer: a French intergroup study. J Clin Oncol 15: $808-813$

de Gramont A, Figer A, Seymour M, Homerin M, Hmissi A, Cassidy J, Boni C, Cortes-Funes H, Cervantes A, Freyer G, Papamichael D, Le Bail N, Louvet C, Hendler D, de Braud F, Wilson C, Morvan F, Bonetti A (2000) Leucovorin and fluorouracil with or without oxaliplatin as first-line treatment in advanced colorectal cancer. J Clin Oncol 18: 2938-2947

Douillard JY, Cunningham D, Roth AD, Navarro M, James RD, Karasek P, Jandik P, Iveson T, Carmichael J, Alakl M, Gruia G, Awad L, Rougier P (2000) Irinotecan combined with fluorouracil alone as first-line treatment for metastatic colorectal cancer: a multicentre randomised trial. Lancet 355: 1041 - 1047

Goldberg RM, Morton R, Sargent D, Fuchs C, Ramanathan R, Williamson S, Findlay B (2002) N9741: oxaliplatin (oxal) or CPT-11+5-fluorouracil $(5 \mathrm{FU}) /$ leucovorin $(\mathrm{LV})$ or oxal+CPT-11 in advanced colorectal cancer (CRC). Initial toxicity and response data from a GI intergroup study. Proc Am Soc Clin Oncol 21: 128a (abstract 511)

Grothey A, Deschler B, Kroening H, Ridwelski K, Reichardt P, Kretzschmar A, Clemens M, Hirschmann W, Lorenz M, Asperger W, Buechele T, Schmoll H-J (2002) Phase III study of bolus 5-fluorouracil (5FU)/folinic acid (FA) (Mayo) vs weekly high-dose 24h 5FU infusion/FA+oxaliplatin (OXA) (FUFOX) in advanced colorectal cancer (ACRC). Proc Am Soc Clin Onc 21: 129a (abstract 512)

NICE (2002) Guidance on the use of irinotecan, oxaliplatin and raltitrexed for the treatment of advanced colorectal cancer. Technology Appraisal Guidance No. 33. National Institute for Clinical Excellence

Rothenberg ML, Meropol NJ, Poplin EA, van Cutsem E, Wadler S (2001) Mortality associated with irinotecan plus bolus fluorouracil/leucovorin: summary findings of an independent panel. J Clin Oncol 19: $3801-3807$

Saltz LB, Cox JV, Blanke C, Rosen LS, Fehrenbacher L, Moore MJ, Maroun JA, Ackland SP, Locker PK, Pirotta N, Elfring GL, Miller LL (2000) Irinotecan plus fluorouracil and leucovorin for metastatic colorectal cancer. Irinotecan Study Group. N Engl J Med 343: 905 - 914

Sargent DJ, Niedzwiecki D, O’Connell MJ, Schilsky RL (2001) Recommendation for caution with irinotecan, fluorouracil and leucovorin for colorectal cancer. N Engl J Med 345: $144-145$

Saunders MP, Valle JW (2002) Why hasn't the National Institute been 'NICE' to patients with colorectal cancer? Br J Cancer 86: 1667 - 1669

Tournigand C, Louvet C, Quinaux E, Andre T, Lledo G, Flesch M, Ganem G, Landi B, Colin P, Denet C, Mery-Mignard D, Riise M-L, Buyse M, de Gramont A (2001) FOLFIRI followed by FOLFOX versus FOLFOX followed by FOLFIRI in metastatic colorectal cancer (MCRC): final results of a phase III study. Proc Am Soc Clin Oncol 20: 124a (abstract 494)

\section{Reply I: Call for NICE to review urgently their guidance concerning first-line chemotherapy for metastatic colorectal}

\section{cancer}

\author{
MP Saunders*,' and JW Valle' \\ 'Department of Clinical Oncology, Christie Hospital NHS Trust, Wilmslow Road, Withington, Manchester, M20 9BX, UK
}

British Journal of Cancer (2003) 88, I 153 - I I 54. doi: I0.1038/sj.bjc.600849 www.bjcancer.com

(c) 2003 Cancer Research UK

Sir,

In our editorial 'Why hasn't the National Institute been NICE to patients with colorectal cancer', we highlighted the disparity of

\footnotetext{
*Correspondence: Dr M Saunders,

E-mail: mark.saunders@christie-tr.nwest.nhs.uk
}

treatment in England and Wales compared to other industrialised countries, particularly with respect to the poor 5-year survival figures. Our concerns focused on the conclusions reached by the NICE panel in the face of two prospective, randomised trials involving more than 1000 patients showing a survival advantage in 
1154

favour of first-line irinotecan-based therapy (Douillard et al, 2000; Saltz et al, 2000).

We only referred to the MRC CRO8 (FOCUS) study since the NICE panel recommended entering patients into this trial and were planning to review their guidance when the results from this study are available. We never questioned the ethical validity of the FOCUS study. We simply pointed out that NICE seem to have linked their guidance very closely to this study and feel that they have frankly misinterpreted the many positive studies from here and abroad. NICE also failed to appreciate that patients who were randomised into the two oxaliplatin arms were unable to receive irinotecan at any point, even though they supported second-line use of this drug. We were not questioning the FOCUS study; we simply alluded to this disparity created by NICE. Since our editorial was published, the FOCUS study has, in our opinion, quite rightly added a third-tier of treatment, so allowing all patients to receive both oxaliplatin and irinotecan at some point.
However, according to NICE recommendations, patients who prefer not to be entered into this study should only receive 5Fluorouracil and folinic acid (5FU/FA) 'up-front', unless they fall into the very small group of patients that have potentially operable liver metastases.

With the widespread availability of the internet and because we need to provide enough information to allow patients to give informed consent, they are quite rightly questioning the NICE guidance in a similar manner to the 28 colorectal oncologists who wrote to the Daily Telegraph in June. Patients are also rightly concerned that the NICE guidance was influenced too much by government funding constraints rather than clinical-effectiveness. We would strongly urge NICE to consider a fresh review before 2005 , based on both the convincing existing data (Douillard et al, 2000; Saltz et al, 2000) and the rapidly emerging new data using all three drugs - planned or unplanned (Tournigand et al, 2001; Goldberg et al, 2002).

\title{
REFERENCES
}

Douillard JY, Cunningham D, Roth AD, Navarro M, James RD, Karasek P, Jandik P, Iveson T, Carmichael J, Alakl M, Gruia G, Awad L, Rougier P (2000) Irinotecan combined with fluorouracil compared with fluorouracil alone as first-line treatment for metastatic colorectal cancer: a multicentre randomised trial. Lancet 355: $1041-1047$

Goldberg RM, Morton RF, Sargent DJ, Fuchs C, Ramanathan RK, Williamson S, Findlay B (2002) Oxaliplatin or CPT11+5-fluorouracil/ leucovorin or Oxa+CPT11 in advanced colorectal cancer (ACRC). Efficacy and safety results from a North American Gastrointestinal Intergroup Study (N9741). Abstract 6, Perspectives in Colorectal Cancer, A consensus meeting, Fourth International Conference, Barcelona, 2002

Saltz LB, Cox JV, Blanke C, Rosen LS, Fehrenbacher L, Moore MJ, Maroun JA, Ackland SP, Locker PK, Pirotta N, Elfring GL, Miller LL (2000) Irinotecan plus fluorouracil and leucovorin for metastatic colorectal cancer. Irinotecan Study Group [see comments]. N Engl J Med 343: 905 914

Tournigand C, Louvet C, Quinaux E, Andre T, Lledo G, Flesch M, Ganem G, Landi B, Colin P, Denet C, Mery-Mignard D, Risse M, Buyse M, de Gramont A (2001) FOLFIRI followed by FOLFOX versus FOLFOX followed by FOLFIRI in metastatic colorectal cancer (MCRC): final results of a phase III study. Proc Am J Clin Oncol 20: 124a (abstract 494)

\section{Reply 2: NICE guidelines on drugs for colorectal cancer}

\author{
PJ Ross ${ }^{1,2}$ and D Cunningham*, 1,2 \\ 'Royal Marsden Hospital, London, UK; ${ }^{2}$ Department of Medicine, Royal Marsden Hospital, Downs Road, Sutton, Surrey SM2 5PT, UK
}

British Journal of Cancer (2003) 88, I I54- | |55. doi: I0.1038/sj.bjc.6600853 www.bjcancer.com

(c) 2003 Cancer Research UK

Sir,

Drs Mason, Johnson and Rudd suggest that criticism of the guidance issued by the National Institute for Clinical Excellence (NICE) regarding the use of irinotecan and oxaliplatin in the treatment of patients with advanced colorectal cancer may have implications for the FOCUS trial (Cunningham et al, 2002; Mason et al, 2002; NICE, 2002; Saunders and Valle, 2002). However, the reason for criticism of the NICE guidance is due to the overwhelming evidence that access to the three drugs 5fluorouracil, irinotecan and oxaliplatin is the optimal therapeutic approach to metastatic colorectal cancer. Subsequent to this

*Correspondence: Dr D Cunningham: Department of Medicine, Royal Marsden Hospital, Downs Road, Sutton, Surrey SM2 5PT, UK:

E-mail: david.cunningham@icr.ac.uk guidance entry into the revised FOCUS protocol is the only way that patients in the UK can access all these agents. Therefore, patients not participating in the FOCUS trial will receive suboptimal therapy. Although the median survival for FOCUS of 16 months is encouraging, and certainly a major step forward over CRO6 with a median survival of approximately 10 months (Maughan et al, 2002), it remains significantly less than that for patients treated with all three agents in randomised trials such as N9741 (Goldberg et al, 2002) and the Tournigand trial (Tournigand et al, 2001) with median survivals of 18.6 months (data presented at the American Society of Clinical Oncology, Orlando, 2002) and approximately 21 months (data presented at the American Society of Clinical Oncology, San Francisco, 2001). 